\title{
Bulk milk somatic cell counts are related to bulk milk total bacterial counts and several herd-level risk factors in dairy goats
}

\author{
G. Koop, ${ }^{1}$ M. Nielen, and T. van Werven \\ Department of Farm Animal Health, Faculty of Veterinary Medicine, Utrecht University, 3584 CL Utrecht, the Netherlands
}

\begin{abstract}
The aim of this study was to describe the temporal variation in bulk milk somatic cell count (BMSCC) on Dutch dairy goat farms and to assess the correlation of BMSCC with bulk milk total bacterial counts (BMTBC) and with several herd management factors. Bulk milk somatic cell count and BMTBC data were recorded from $90 \%$ of the dairy goat farms in the Netherlands over the years 2005 to 2007. Farm characteristics and management information was collected by means of questionnaires. The bulk milk data and the questionnaire data were linked and linear mixed models were used to identify risk factors for increased BMSCC and BMTBC. Bulk milk somatic cell count was found to display a distinct pattern throughout the year, being highest around December and lowest around June. Bulk milk somatic cell count correlated to BMTBC (r $=0.4$ ). Significant factors in the BMSCC model were month in lactation, treating mastitic animals instead of culling, caprine arthritis encephalitis status, milk fever prevalence, and liner material. Month in lactation and treating mastitic animals instead of culling were also significant in the BMTBC model. In the high-BMSCC period, a higher number of goats with an extended lactation significantly reduced the BMSCC. Thus, this study indicates that mastitis-related factors account for some of the variation in BMSCC and BMTBC levels between dairy goat herds. It shows that intramammary infection is probably the most important factor driving the correlation between BMSCC and BMTBC, suggesting that programs to improve udder health may have a positive effect on both BMSCC and BMTBC.
\end{abstract}

Key words: bulk milk, somatic cell count, total bacterial count, dairy goat

\section{INTRODUCTION}

Bulk milk somatic cell count (BMSCC) can be used to evaluate the udder health status of a herd and can

Received February 5, 2009.

Accepted May 12, 2009.

${ }^{1}$ Corresponding author: g.koop@uu.nl therefore be a useful tool to improve herd management. In cows, various factors associated with BMSCC have been identified (Khaitsa et al., 2000; Jayarao et al., 2004). In sheep, a range of factors that affect BMSCC has been studied, such as milking technique and dry-ewe therapy practices (Gonzalo et al., 2005). In goats, several factors influencing BMSCC have been described; for example, the importance of neutrophils in the composition of high BMSCC (Droke et al., 1993), an increase in BMSCC during lactation (Paape et al., 2007), the seasonal variation in BMSCC (Zeng et al., 1999b), and the effect of hygiene-sanitary management conditions (Delgado-Pertiñez et al., 2003). However, several herd management factors that are possibly related to BMSCC on dairy goat farms such as milking technique, housing conditions, drying-off strategies, disease prevalence, and breed effects have until now not been investigated. Furthermore, to our knowledge no articles describing the goat milk BMSCC situation in northwestern Europe are available. This region differs from the situation described in the aforementioned US papers (Droke et al., 1993; Zeng et al., 1999b; Paape et al., 2007), because in the European Union there is currently no legal limit for goat milk BMSCC. Furthermore, it differs from other parts of Europe. For example, goats in this region are kept in an intensive system, not pastured, and are exclusively machine milked; this is in contrast to the Spanish situation described by DelgadoPertiñez et al. (2003), where hand milking is common and goats are kept more extensively.

Bulk milk total bacterial count (BMTBC) is commonly used to evaluate the bacteriological quality of bulk milk. Bulk milk total bacterial count studies of goat milk tend to focus on the microbial composition of the milk, and only 2 papers describe factors causing variation in BMTBC in extensive systems with relatively small flocks of fewer than 180 goats (Tirard-Collet et al., 1991; Zweifel et al., 2005). Both articles point out that the factors that are most important for achieving a low BMTBC are good hygiene, rapid cooling and refrigeration, and frequent collection of the milk. The current study was performed in a more intensive and industrialized setting, with larger flocks. This means that other factors affecting the BMTBC such as herd 
management may be important. In sheep and cattle, BMTBC was shown to correlate with BMSCC (Jayarao et al., 2004; Rysanek and Babak, 2005; Gonzalo et al., 2006); in goats, this relationship has been considered, but no such correlation was observed to be significant because of small sample sizes (Foschino et al., 2002).

This study examined relationships between BMSCC and several herd-level risk factors for high BMSCC. It included BMTBC to assess its possible correlation with BMSCC and its relationship with risk factors related to BMSCC. The purpose of this paper was 1) to describe the variation in BMSCC and BMTBC throughout the year and their correlation, and 2) to identify herd-level risk factors for high BMSCC and high BMTBC in dairy goat herds.

\section{MATERIALS AND METHODS}

\section{Data Collection}

BMSCC and BMTBC Data Collection. Bulk milk data (BMSCC and BMTBC) from Dutch goat farms was collected from 287 farms in 2005, 300 farms in 2006, and 317 farms in 2007. These farms delivered to 7 goat milk processing companies. The survey included approximately $90 \%$ of all dairy goat farms in the Netherlands. Bulk milk samples were collected routinely twice every month by the milk lorry drivers. The samples were taken in plastic vials and transported on melting ice to the processors. From there, the samples were refrigerated at 2 to $4^{\circ} \mathrm{C}$ and transported to the central Dutch laboratory for farm milk analysis. Bulk milk somatic cell count was determined with the Fossomatic 5000 (Foss, Hillerød, Denmark). Bulk milk total bacterial count was measured with the BactoScan FC150 (Foss). The equipment was calibrated with cow milk.

Questionnaire Data. Our questionnaire, designed to study various herd characteristics that could be related to variation in BMSCC, included questions on breed, farm size, farm management, milking routine, milking machine settings, yearly milk production, number of cases of clinical mastitis, treatment of clinical mastitis, prevalence of various other diseases, housing, and the time of kidding. The questionnaire is available from the corresponding author. The majority of the questions were closed; if necessary, space was available to write in alternatives to the options given. All questions were explicitly related to the situation on the farm in the year 2007. The questionnaire contained 5 pages with 50 questions. It was pretested on 3 farmers, after which a few questions were changed. In January 2008, the questionnaires, together with an explanatory letter and a business reply envelope, were mailed to the farmers who had delivered milk to 1 of the 7 processing companies during 2007. Because not all addresses were available, the questionnaire was sent to only 273 out of the 317 farms. Farmers who did not respond after 3 wk received a postcard reminder. Two weeks later, the remaining nonrespondents were asked by phone to complete the questionnaire.

\section{Data Analysis}

Descriptive Statistics. All BMSCC and BMTBC data were normalized by $\log _{10}$-transformation (LBMSCC and LBMTBC, respectively). Normality of these variables was investigated by visual inspection of the histograms and the Shapiro-Wilk test statistic. Measures of central tendency and dispersion were used to describe these data. The correlation between LBMSCC and LBMTBC was determined in 2 ways. First, mean values of LBMSCC and LBMTBC were calculated per farm per year. Pearson product-moment correlation coefficient was calculated between mean LBMSCC and mean LBMTBC for each year. Because Pearson's r assumes a normal distribution of the variables, we also calculated its nonparametric equivalent, Spearman's rank correlation coefficient $(\rho)$, which measures a not necessarily linear association between 2 variables that may be ordinal. Second, normality of the variables at all 72 time points (24 time points per year over $3 \mathrm{yr}$ ) was assessed and appropriate correlation coefficients between the 2 variables were calculated for each time point separately.

LBMSCC and LBMTBC Risk Factor Models. The questionnaire data were entered using Epi Info (version 3.4.1, Centers for Disease Control and Prevention, Atlanta, GA). Many questions were categorized into binary variables or categorical variables with 3 classes. The question about cleaning udders of the goats was transformed into a binary variable (denoted udder cleaning) indicating farmers who never performed any cleaning versus farmers who cleaned the udder when it was visibly dirty or routinely. The question that asked about what farmers did with animals suffering from clinical mastitis was categorized into a binary variable (denoted mastitic animals); farmers who treated $>50 \%$ of the animals suffering from clinical mastitis were separated from farmers who culled $>50 \%$ of all mastitic animals without any treatment. The question about the number of goats having an extended lactation was transformed into a variable (denoted extended lactations), indicating whether the percentage of goats on the farm having an extended lactation in 2007 was $0 \%$, between 0 and $50 \%$, or more than $50 \%$. The variable based on a question about floor surface available for the milking goats (denoted space per goat) was 
Table 1. Variables with unconditional associations with mean $\log _{10}$ bulk milk somatic cell count (LBMSCC) or mean $\log _{10}$ bulk milk total bacterial count (LBMTBC) in the complete data set or in one of the subsets

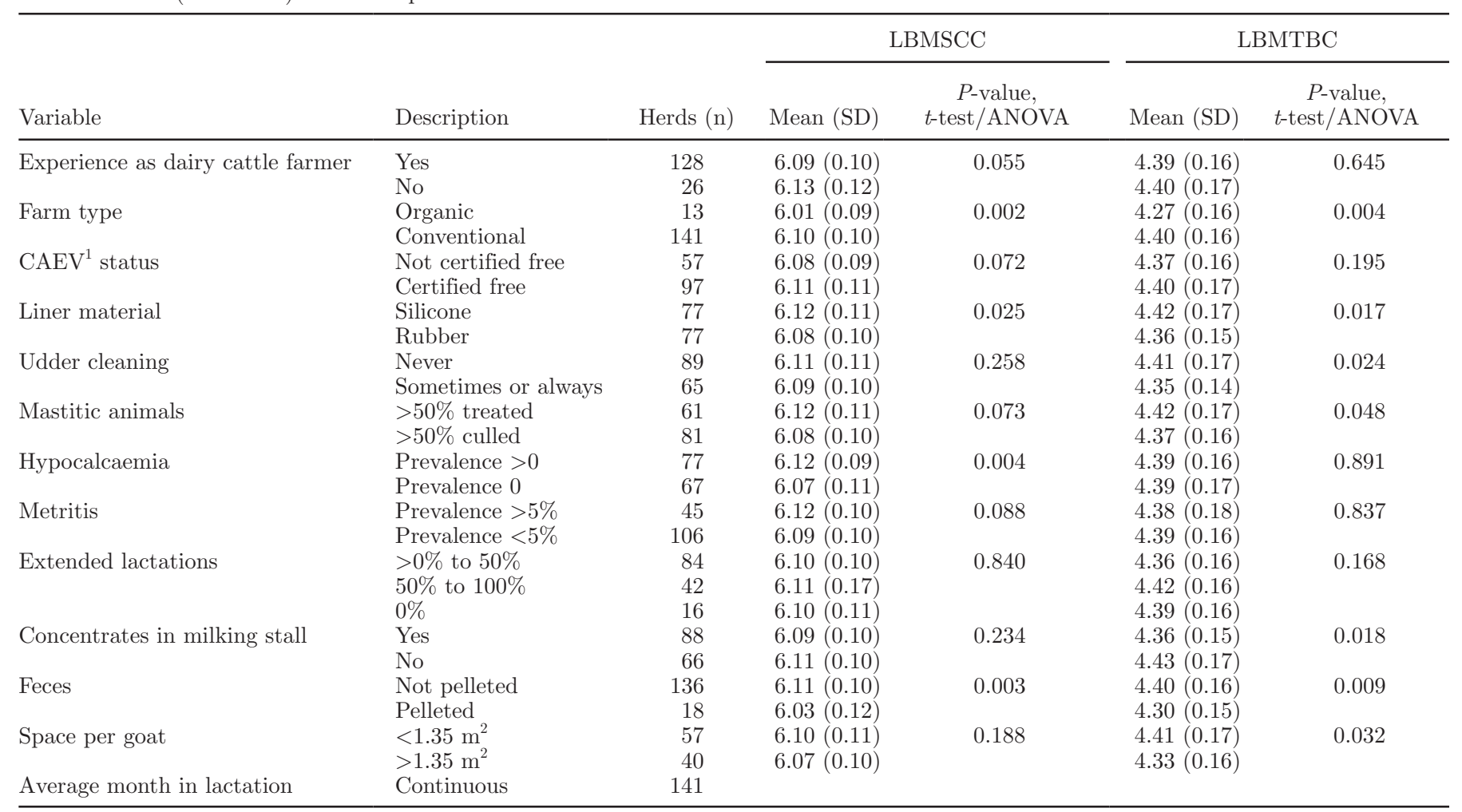

${ }^{1} \mathrm{CAEV}=$ caprine arthritis encephalitis virus.

dichotomized in farms with more or less than $1.35 \mathrm{~m}^{2} /$ goat. The average milk production per goat was calculated based on the total yearly farm production and the number of lactating animals. The question that asked for the number of goats that kidded in each month of 2007 was transformed into a new continuous variable (denoted average month in lactation) as follows: the number of goats that kidded in a certain month, divided by the total number of goats that kidded in all months of the year is the fraction of births in that month. This fraction of animals was assumed to be on average 0.5 mo in lactation in this month and on average $1.5 \mathrm{mo}$ in lactation in the next month, and so on. The average month in lactation for February, for example, was calculated by summing the fraction (February) $\times 0.5$ + fraction (January) $\times 1.5+$ fraction (December) $\times$ 2.5 , and so on. This was calculated for every month of the year, assuming that the kidding pattern reported in the questionnaire for 2007 was the same as in the previous year.

All questionnaire-based variables were checked for unconditional associations with the dependent variables LBMSCC and LBMTBC. Variables with unconditional $P$-values of $<0.10$ (Table 1 ) were tested in multiple regression models. These variables were first checked for collinearity. If the Pearson Chi-squared test of 2 independent variables had a $P<0.10$, then only the most biologically meaningful variable was included in the model building process. For example, the variable available space per goat was considered more biologically meaningful than farm type (organic or conventional).

$\log _{10}$-transformed BMSCC and $\log _{10}$-transformed BMTBC were the dependent variables in 2 linear mixed models, and the variables derived from the questionnaire were tested as independent variables. The 2 models were built with a random farm effect to correct for the repeated measures within farms. Random slopes, random intercepts, or both were allowed if significant, based on the likelihood-ratio test. Processing company was forced into the models as a fixed factor to prevent possible confounding on this variable. Time point of measurement was also forced in as a fixed factor in the BMSCC model to model the changes in BMSCC throughout the year.

Nonsignificant $(P>0.05)$ variables were excluded from the saturated models through backward selection. Presence of confounding was checked for based on the change in the $\beta$-estimate after exclusion of a variable. A change in the estimate of $>30 \%$ was deemed to indicate confounding. First-order autoregressive and compound symmetry covariance structures were considered and 
Table 2. Descriptive statistics of $\log _{10}$ bulk milk somatic cell count (LBMSCC) and $\log _{10}$ bulk milk total bacterial count (LBMTBC) data of Dutch dairy goat farms in 2005 to 2007

\begin{tabular}{lcccccc}
\hline Statistic & Year & Herds $(\mathrm{n})$ & Minimum & Maximum & Mean & SD \\
\hline Mean LBMSCC & 2005 & 287 & 5.69 & 6.35 & 6.06 & 0.12 \\
& 2006 & 300 & 5.58 & 6.40 & 6.07 & 0.12 \\
Mean LBMTBC & 2007 & 317 & 5.74 & 6.45 & 6.09 & 0.12 \\
& 2005 & 287 & 3.92 & 5.00 & 4.37 & 0.18 \\
& 2006 & 300 & 3.96 & 5.02 & 4.42 & 0.17 \\
& 2007 & 317 & 3.94 & 5.06 & 4.41 & 0.17 \\
\hline
\end{tabular}

the covariance structure with the lowest Akaike's information criteria was included if it yielded a significant improvement of the model.

The fit of the models and the assumptions of homoscedasticity, normality, and linearity were checked by visual inspection of the plots of standardized residuals against standardized predicted values, quantile-quantile plots of standardized residuals, and plots of standardized residuals against predictor variables. Weighted variance structures were modeled if necessary based on these plots and the significance of the improvement of the model was assessed with likelihood-ratio tests. When the quantile-quantile plots revealed that the residuals of the final models were not sufficiently normally distributed, Poisson regression models with random effects were fit on the data, to see if the factors from the linear mixed models were still significant.

Variance components for random factors were estimated in the empty models for LBMSCC and LBMT$\mathrm{BC}$ according to the REML function, using the GLM - variance components procedure in SPSS for Windows (version 15.0.1, SPSS Inc., Chicago, IL).

Additional Analyses. Three additional models were built. Subsets of the data in the high- (first and last 3 measurements of 2007) and the low-LBMSCC (10th through 15th measurement of 2007) period were used as dependent variables in 2 mixed models. Questionnaire-based predictor variables with unconditional $P$-value $<0.10$ in these subsets were offered to the models. The third model was a multiple linear regression model, in which the range between the minimum and maximum LBMSCC value in the year 2007 was used as dependent variable. These additional models were built in the same way as described previously.

All analyses were carried out in SPSS for Windows (version 15.0.1, SPSS Inc.), except for the mixed models, which were built in $\mathrm{R}$ (version 2.7.1, R Foundation for Statistical Computing, Vienna, Austria) using the LME function from the NLME-library (Pinheiro et al., 2008).

\section{RESULTS}

\section{Descriptive Statistics}

The dairy goat farms participating in this study had an average herd size of approximately 550 lactating ani- mals. The most common breeds were the Saanen goat and the Dutch White milking goat, which is closely related to Saanen. Some farmers milked once or thrice a day, but the majority (>95\%) milked twice a day. The farms were highly mechanized: animals were machine milked and most farms (>60\%) used automatic cluster removal. The milk was collected in bulk tanks and picked up 2 to 3 times each week. Most farms have a strong seasonal kidding pattern. More than $50 \%$ of all births occurred in February and March and more than $75 \%$ occurred between January and April. The average production per animal was approximately $900 \mathrm{~kg}$ of milk/animal per year, but differences between farms were large (with per-animal yields varying from 600 to $1,300 \mathrm{~kg}$ of milk/yr).

The total number of farms in this study increased from 287 in 2005 to 317 in 2007. In the years 2005, 2006 , and 2007, respectively, a total of $6,228,6,753$, and 6,919 records for BMSCC and 6,160, 6,692, and 6,908 records for BMTBC were available. Descriptive statistics of farm mean LBMSCC and farm mean LBMTBC per year are given in Table 2 . $\log _{10}$-transformed BMSCC follows a relatively stable pattern over the years. It is high at the turn of the year and low in the summer months (Figure 1a). $\log _{10}$-transformed BMTBC also seems to display a yearly pattern (Figure $1 \mathrm{~b}$ ), but this is less rigid than the LBMSCC pattern.

According to the Shapiro-Wilk test, the distribution of mean LBMTBC values was significantly different from normal in the years 2005 and $2007(P=0.002$ and $P=0.005$ respectively). The distribution of mean LBMSCC values differed from normality in $2006(P$ $=0.004)$. The correlation coefficients describing the relationship between farm mean LBMSCC and farm mean LBMTBC for the 3 years are given in Table 3 . According to the Shapiro-Wilk test, the distribution of LBMSCC at each of the 72 measurement points did not differ from normality most of the time, whereas LBMTBC values were never normally distributed $(P<$ 0.001). Spearman's $\rho$, calculated for each measurement point, is shown in Figure 1c. The amount of co-variation was not constant over the different points in time, the lowest correlation coefficient being $\mathrm{r}=0.19$ and the highest being $\mathrm{r}=0.55$. 

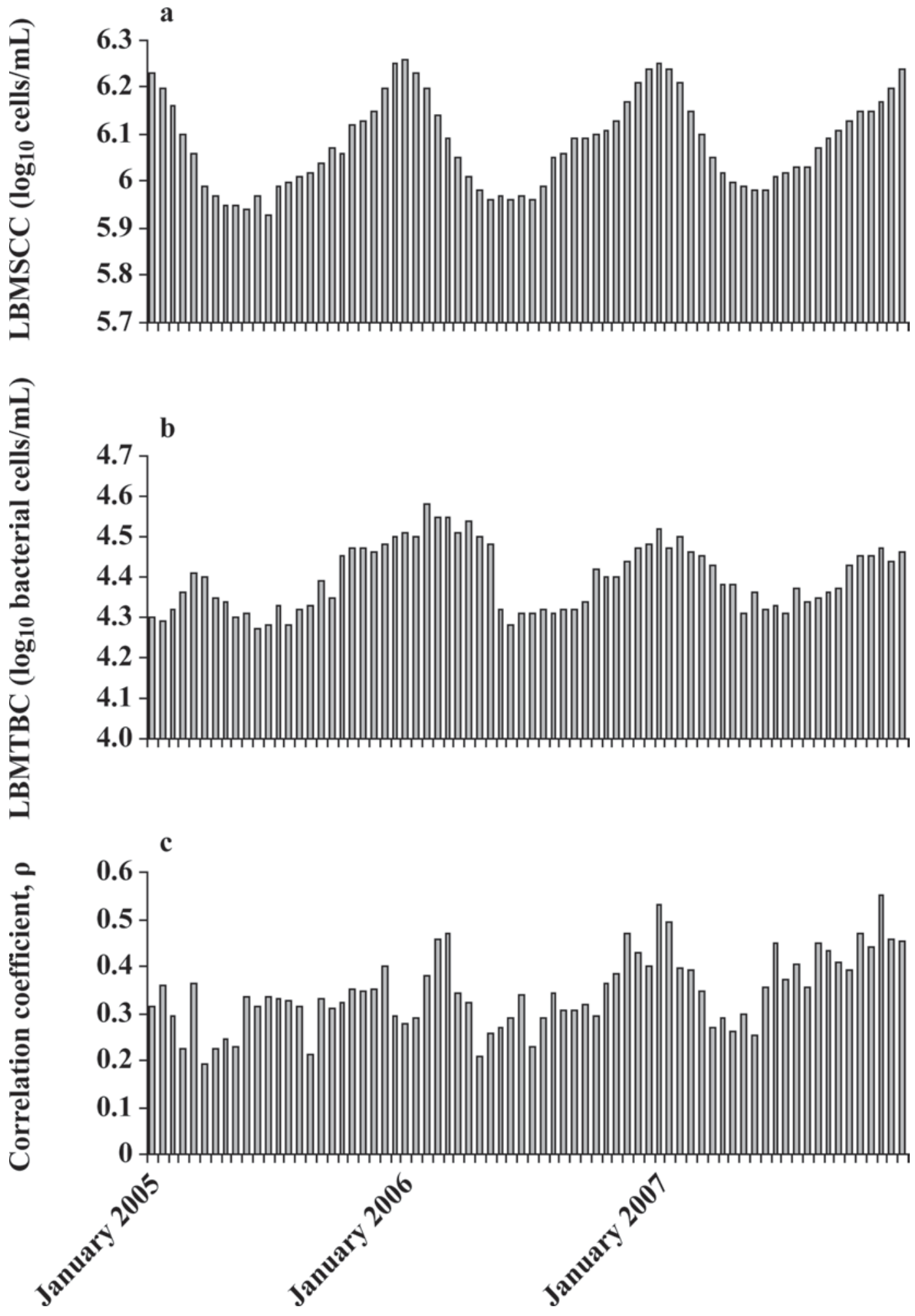

Figure 1. a) Average $\log _{10}$ bulk milk somatic cell count (LBMSCC) measurements, b) average $\log _{10}$ bulk milk total bacterial count (LBMTBC) measurements, and c) Spearman's rank correlation coefficient $\rho$ between LBMSCC and LBMTBC, in 287 to 317 Dutch dairy goat herds measured on 24 time points per year during the years 2005 through 2007. 
Table 3. Correlation coefficients according to Pearson and Spearman between farm mean $\log _{10}$ bulk milk somatic cell count and farm mean $\log _{10}$ bulk milk total bacterial count

\begin{tabular}{lccc}
\hline Year & Pearson's r & Spearman's $\rho$ & $P$-value \\
\hline 2005 & 0.395 & 0.386 & $<0.001$ \\
2006 & 0.399 & 0.462 & $<0.001$ \\
2007 & 0.430 & 0.466 & $<0.001$ \\
\hline
\end{tabular}

\section{LBMSCC and LBMTBC Risk Factor Models}

Of the 273 questionnaires that were sent out, 163 were completed and returned. Of these, 9 questionnaires could not be linked to the bulk milk data because the farm identification number was not provided. The actual response rate was therefore $56 \%$. The nonrespondents were asked by telephone why they chose not to participate. Lack of time was the usual reason given. Responding farmers were representative of the Dutch dairy goat farmers' population. Their mean LBMSCC in 2007 was not significantly different from nonrespondents $(P=$ 0.642). They had only a slightly lower mean LBMTBC than nonrespondents (4.39 vs. $4.43 \log _{10}$ bacterial cells/ $\mathrm{mL}, P=0.026)$. The number of organic farmers among them $(8 \%)$ was comparable to the number of organic farmers in the population (10\%).

The components of variance for LBMSCC were estimated at $\sigma^{2}$ (farm) $=0.011, \sigma^{2}$ (processing company) $=0.001$, and $\sigma^{2}$ (residual $)=0.020$. Thus, $34 \%$ of the variance in LBMSCC is between farms and $3 \%$ of the variance is between processing companies. The components of variance for LBMTBC were estimated at $\sigma^{2}$ $($ farm $)=0.022, \sigma^{2}$ (processing company $)=0.002$, and $\sigma^{2}$ (residual $)=0.061$. This indicates that $26 \%$ of the variance in LBMTBC is between farms and $2 \%$ of the variance is between processing companies.

The coefficients of the final linear mixed models for LBMSCC and LBMTBC are presented in Table 4. The fit of these models improved significantly by adding a first-order autoregressive covariance structure, but the residuals of these final models were not sufficiently normally distributed, according to the quantile-quantile plots. The factors from the final linear mixed models were also significant in Poisson models with a random effect. This was the case for both the LBMSCC and LBMTBC models. For ease of interpretation, we chose to report the linear mixed models.

\section{Additional Analyses}

The coefficients of the final linear mixed models for LBMSCC in the low and high periods are presented in Table 5. These models also had a problem with normality of the residuals that could not completely be solved. Nevertheless, the same variables were significant in Poisson models as in the linear mixed models. The final linear regression model for the range of LBMSCC (not shown) included only the proportion of extended lactations. A higher proportion of extended lactations was correlated with a lower range between minimum and maximum LBMSCC on a farm.

\section{DISCUSSION}

\section{Descriptive Statistics}

It is generally accepted that goat milk cell counts are higher than cow milk cell counts. Even for udder halves

Table 4. Coefficients $(\beta)$ and confidence intervals (CI) around $\beta$ of linear mixed regression models for $\log _{10}$ bulk milk somatic cell count (LBMSCC) and $\log _{10}$ bulk milk total bacterial count (LBMTBC) with processor and measurement time point forced in as fixed effects and a random effect of farm

\begin{tabular}{|c|c|c|c|c|c|}
\hline \multirow[b]{2}{*}{ Variable } & \multirow[b]{2}{*}{ Status } & \multicolumn{2}{|c|}{ LBMSCC, $\mathrm{n}=124$ farms } & \multicolumn{2}{|c|}{ LBMTBC, $\mathrm{n}=133$ farms } \\
\hline & & $\beta$ & $95 \%$ CI $(\beta)$ & $\beta$ & $95 \%$ CI $(\beta)$ \\
\hline Average month in lactation & Continuous & 0.02 & 0.01 to 0.02 & 0.02 & 0.01 to 0.02 \\
\hline Mastitic animals & $\begin{array}{l}>50 \% \text { treated } \\
>50 \% \text { culled }\end{array}$ & $\begin{array}{l}0.03 \\
0\end{array}$ & 0.00 to 0.07 & $\begin{array}{l}0.07 \\
0\end{array}$ & 0.02 to 0.13 \\
\hline $\mathrm{CAEV}^{1}$ status & $\begin{array}{l}\text { Not certified free } \\
\text { Certified free }\end{array}$ & $\begin{array}{c}-0.05 \\
0\end{array}$ & -0.09 to 0.02 & 0 & \\
\hline Liner material & $\begin{array}{l}\text { Silicone } \\
\text { Rubber }\end{array}$ & $\begin{array}{l}0.04 \\
0\end{array}$ & 0.01 to 0.07 & & \\
\hline Feces & $\begin{array}{l}\text { Not pelleted } \\
\text { Pelleted }\end{array}$ & & & $\begin{array}{l}0.12 \\
0\end{array}$ & 0.05 to 0.20 \\
\hline Concentrates in milking stall & $\begin{array}{l}\text { Yes } \\
\text { No }\end{array}$ & & & $\begin{array}{l}-0.07 \\
0\end{array}$ & -0.13 to -0.02 \\
\hline
\end{tabular}

${ }^{1} \mathrm{CAEV}=$ caprine arthritis encephalitis virus. 
Table 5. Coefficients $(\beta)$ and confidence intervals (CI) around $\beta$ of linear mixed regression models for $\log _{10}$ bulk milk somatic cell count (LBMSCC) in the low and in the high cell count period with processor and measurement time point forced in as fixed effects and a random effect of farm

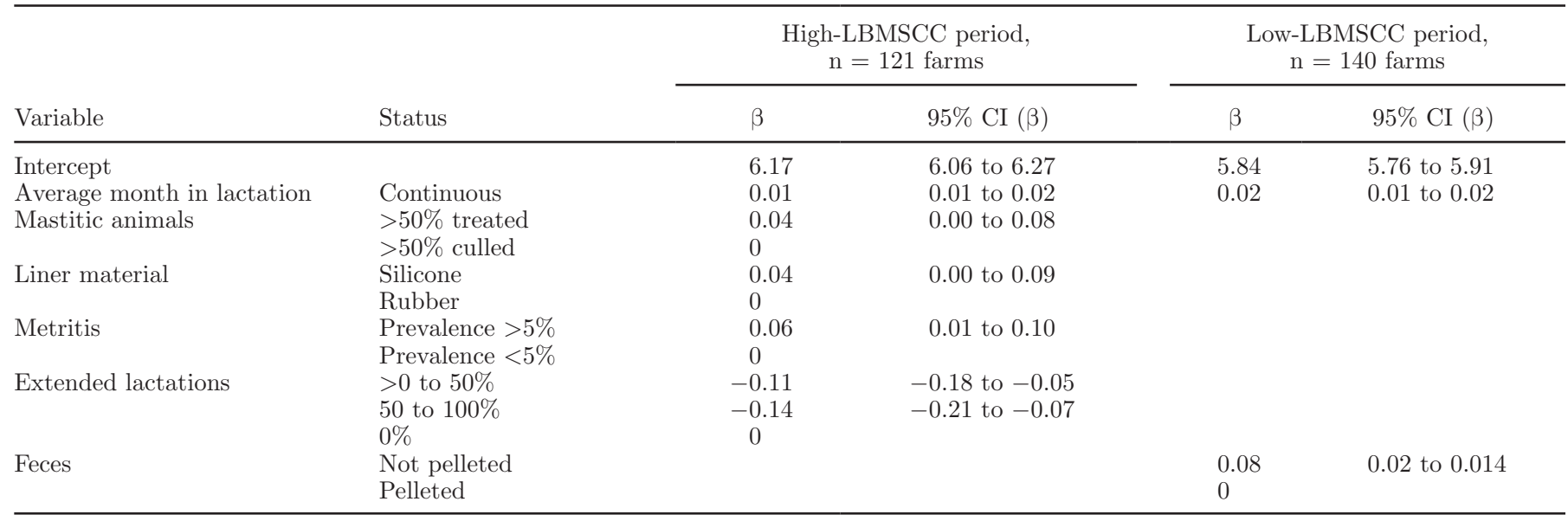

free from IMI, literature values for SCC vary between 0.27 and $2.0 \times 10^{6}$ cells $/ \mathrm{mL}$ (Paape et al., 2001). Table 6 summarizes BMSCC values that have been reported in other papers. Most of these report lower BMSCC values than were found in the present study. Most studies, though, were based upon small sample sizes and information on kidding pattern of the herds was not always given. Herd sizes in those studies were generally much smaller than in the present study and most of the studies are more than $5 \mathrm{yr}$ old. Therefore, those farms probably are less mechanized than the farms included in this study and thus farm management in general differs between this study and previous reports. The various breeds that were used in the different studies may also explain part of the difference in BMSCC. The calibration method in the BMSCC determination is another factor that may have been important. Calibration of the Fossomatic apparatus with goat milk instead of with cow milk standards may lead to lower BMSCC values, because goat milk standards are known to give approximately $25 \%$ lower SCC estimates than cow milk standards (Zeng et al., 1999a). Except for Zeng et al. (1999b), calibration method was not mentioned by the authors of other studies. We assume that in those cases the conventional cow milk calibration was used.

Yearly average BMSCC increased during the years of this study. Such a trend was observed by Paape et al. (2007) in USDA data; also, Pirisi et al. (2007) described an increase in yearly average SCC in the Poitou-Charentes area of France. No satisfactory explanation is given for this phenomenon. Pirisi et al. (2007) mention the intensification of milk production and the increase in milk yield as possible explanations. Paape et al. (2007) point out that the increase in cell counts is the more surprising because of recent emphasis to lower the legal limit for goat milk SCC in the United States. Although the observed differences between the years were significant in paired $t$-test, these differences may not be very important and possible reasons to explain these findings are mainly speculative.

The seasonal BMSCC pattern we observed has been described by several authors (Zeng et al., 1999b; Foschino et al., 2002; Haenlein, 2002). Bulk milk somatic cell count was high at the turn of the year and low during the summer months. This is generally explained by the seasonal breeding pattern of goats and the fact that goat milk SCC increases with stage of lactation (Paape et al., 2001, 2007; Haenlein, 2002).

\section{Correlation Between LBMSCC and LBMTBC}

A moderate correlation coefficient of approximately 0.4 was observed between mean LBMSCC and mean LBMTBC. The average of the correlations between LBMSCC and LBMTBC on the different time points throughout the year 2007 was also approximately 0.4 . This means that $16 \%$ of the variation in LBMTBC may be explained by variation in LBMSCC or vice versa. The correlation between SCC and TBC on composite milk samples of individual goats has been estimated at $r=0.44$ (Zeng and Escobar, 1995) and $r=0.14$ (Zeng and Escobar, 1996). Other studies found no correlation (Park and Humphrey, 1986; Park, 1991), but had small sample sizes. Similarly, they report no significant correlation between BMSCC and BMTBC in bulk milk (Tirard-Collet et al., 1991; Foschino et al., 2002). In sheep, however, a correlation between BMSCC and BMTBC of $r=0.23$ was found to be significant (Gonzalo et al., 2006). Also in cattle, a correlation $(r=0.18)$ between BMSCC and BMTBC was observed by Rysanek and 


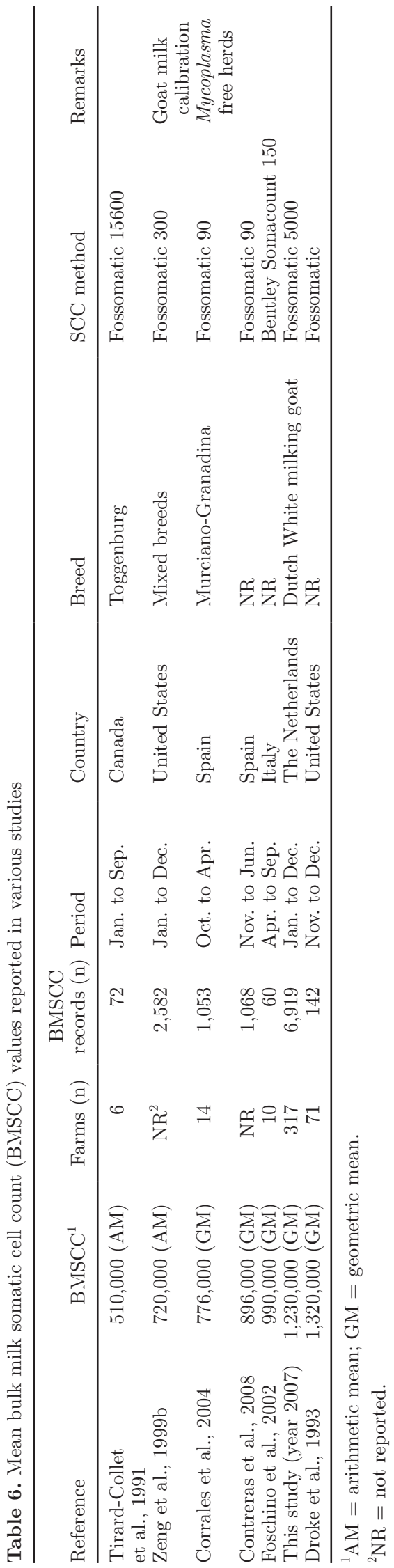

Babak (2005). Jayarao et al. (2004) reported a correlation of $\mathrm{r}=0.32$ between BMSCC and bulk milk standard plate count and they showed that changes in BMSCC also reflect the frequency of isolation of several mastitis pathogens. In addition, Schukken et al. (2003) reported that farms with high SCC levels more often had higher bacterial counts.

The co-variation between BMSCC and BMTBC must be caused by one or more factors that have an effect on both variables. We could think of 3 possible causal mechanisms that could explain this correlation. First, milk production level may have an effect on both BMSCC and BMTBC. Each time the liners are attached, there is a risk of milk contamination. When the production level is high, this amount of bacteria is diluted by more milk, resulting in a lower BMTBC. At the same time, a high production level is known to be related to low SCC (Paape et al., 2001). In this study, we did observe an increase in BMTBC with increasing lactation, but no effect of average yearly milk production per goat (based on the total yearly milk production and the number of lactating goats) on BMTBC. A second explanation of the observed correlation may be the hygiene status of the farm, as hypothesized by Gonzalo et al. (2006). Higher BMTBC may reflect poor flock and milking hygiene and so favor a higher frequency of IMI, which in turn causes an increase in BMSCC (Haenlein, 2002). In goats, however, most IMI are caused by Staphylococcus species (Bergonier et al., 2003; Contreras et al., 2007), which are known to be present on the skin more than in the environment. Environmental hygiene in goats is therefore probably less important in the causation of IMI than it is in cows. Nevertheless, good milking hygiene may reduce the transmission of pathogens, and thereby reduce the prevalence of IMI in the herd. The third causal mechanism hypothesizes that IMI itself may cause the observed correlation. The IMI again causes an increase in BMSCC, but also bacteria from the udder are excreted in the milk, thus increasing the BMTBC. Therefore, IMI from causes other than poor hygiene may also result in increased BMTBC. In short, the presence of IMI and insufficient milking hygiene, also leading to IMI, seem to be the most important factors driving the correlation between BMSCC and BMTBC. Our findings that treatment of mastitic animals instead of culling and liner type act as risk factors for both high BMSCC and high BMTBC favor the hypothesis that IMI is an important factor behind the correlation of these variables.

\section{LBMSCC and LBMTBC Risk Factor Models}

The response rate of the questionnaire was good, and no large differences in BMSCC and BMTBC were 
observed between respondents and nonrespondents. Nevertheless, we cannot rule out the possibility of selection bias in our sample. Because nonrespondents had slightly higher BMTBC values than respondents, we expect that respondents are more motivated to improve their milk quality. Therefore, some risk factors for high BMSCC or BMTBC that are present in the population may have remained unidentified in our sample. A second cause of bias that probably has been present in this study is bias due to misclassification. This is a common problem with questionnaires. Validity of questionnaire data is difficult to ascertain (Sargeant and Martin, 1998). In this study, no questionnaire validation was performed. Therefore, answers given by the farmers may not always reflect the true situation on the farm. Furthermore, answers to questions may be biased by unmeasured confounders. This may explain some of the unexpected findings in this study. For instance, an effect of the reported prevalence of hypocalcemia was seen. This disease is uncommon in dairy goats, and therefore not expected to have any measurable effect on BMSCC. It may be that hypocalcemia reflects the quality of the feeding management, and can thus be linked to udder health. Another example of possible confounding may be the effect of caprine arthritis encephalitis virus (CAEV) status. Farms that were certified free from CAEV had higher BMSCC than farms that were not certified free. As Turin et al. (2005) showed, seronegative primiparous goats have lower SCC than seropositive primiparous goats, and as Nord and Ådnøy (1997) found, the same is true for second-parity goats, whereas Luengo et al. (2004) reported no significant difference in SCC between seropositive and seronegative goats. It seems unreasonable, therefore, that what we observed is a true effect of CAEV. It is more plausible that other characteristics of CAEV-free farms cause the effect. For instance, most farms that have a focus on breeding want to be able to sell animals and are, for that purpose, free from CAEV. It is possible that these farms are less concerned about udder health. Furthermore, recently started farms are usually CAEV-free, so CAEV status may also reflect lack of experience of the farmer.

The models had a relatively poor fit on the data. No reasons for this lack of fit could be found. However, the fact that the same parameters were significant in linear regression models as in Poisson regression models indicates that the effect of these variables is robust.

Culling of mastitic animals was associated with lower BMSCC and BMTBC than treatment of mastitic animals. This was surprising, because the incidence of clinical mastitis reported by the farmers was low (on average $2 \%$ per year). Incomplete bacteriological cure of treated animals, which means that animals continue shedding bacteria as well as producing high cell count milk after the end of the treatment, may explain the effect. Furthermore, keeping the diseased animals in the flock may increase the risk of transmission of IMI in the herd. This means that treatment or culling of clinically mastitic animals probably affects the prevalence of subclinical mastitis in the herd. In cattle, it has been stated that failure to cull animals with a history of clinical mastitis may lead to further transmission of contagious mastitis in the herd (Schukken et al., 2003).

Rubber liners were associated with lower BMSCC compared with silicone liners. However, as Bergonier et al. (2003) state, the use of rubber liners seems to be associated with higher tank milk bacterial counts in ewes. In our study, an effect was seen on BMTBC as well, but it was not significant in the final model. Silicone liners may have a higher potential to cause teat-damage and thereby a predisposition for IMI, affecting both BMSCC as BMTBC. No literature is available to support this. The observed effects of the liners however may also be the result of confounding, because liner material is connected to certain milking machine brands. The effect of the milking machine on both BMSCC and BMTBC may be greater than the effect of the liners.

Farms on which goats had mostly pelleted feces had lower BMSCC and lower BMTBC. Dry feces probably causes less contamination of the udders and therefore is associated with lower BMTBC. As we mentioned before, an effect of dirt on mastitis does not seem plausible because mastitis in goats is rarely caused by fecal pathogens. The consistency of the feces is most probably an indicator of feeding management. Feces become less firm when the diet contains more easily digestible energy and, therefore, has a lower fiber content. The association between concentrate feeding and mastitis in cows was hypothesized to be explained by negative effects on immune function, possibly via a mechanism of subacute ruminal acidosis (Valde et al., 2007).

\section{Additional Analyses}

The high-period subset analysis showed that the percentage of extended lactations has a strong effect in this period, lowering the BMSCC. Extended lactation means that a goat is milked for 2 or more years instead of the conventional 1-yr lactation. The goats do not become pregnant during the first year of extended lactation, and therefore the decrease in milk production during the kidding season is less pronounced, causing a smaller increase in SCC in that period (Salama et al., 2005). We did not observe an effect of extended lactations in the complete data set on BMSCC, indicating that this factor reduces only the amount of fluctuation throughout the year, but not the mean BMSCC. 


\section{CONCLUSIONS}

Bulk milk somatic cell counts in goats follow a constant pattern throughout the year, due to the seasonal kidding pattern in goat herds. Cell counts are moderately correlated to bacterial counts and we hypothesize that IMI is an important factor behind this co-variation. Several herd management factors affect SCC of the bulk milk, among which are mastitis-related factors, feeding-related factors and disease-related factors. Extended lactations decrease the SCC during the kidding period, but have no significant effect on the yearly average. Some of the IMI-related factors also affect bacterial counts of the bulk milk, thus adding to the hypothesis that IMI drives the correlation between BMSCC and BMTBC.

\section{ACKNOWLEDGMENTS}

We thank the Dutch dairy goat farmers for their cooperation. J. van Wegen of VKGN is gratefully acknowledged for the supply of bulk milk data. This study was financially supported by the Dutch Dairy Board and the Dutch Association for Quality Assurance in Goat Farming (VKGN).

\section{REFERENCES}

Bergonier, D., R. de Cremoux, R. Rupp, G. Lagriffoul, and X. Berthelot. 2003. Mastitis of dairy small ruminants. Vet. Res. 34:689-716.

Contreras, A., R. E. Miranda, A. Sanchez, C. de la Fe, D. Sierra, C. Luengo, and J. C. Corrales. 2008. Presence of Mycoplasma species and somatic cell counts in bulk-tank goat milk. Small Rumin. Res. 75:247-251.

Contreras, A., D. Sierra, A. Sanchez, J. C. Corrales, J. C. Marco, M. J. Paape, and C. Gonzalo. 2007. Mastitis in small ruminants. Small Rumin. Res. 68:145-153.

Corrales, J. C., A. Sanchez, C. Luengo, J. B. Poveda, and A. Contreras. 2004. Effect of clinical contagious agalactia on the bulk tank milk somatic cell count in Murciano-Granadina goat herds. J. Dairy Sci. 87:3165-3171.

Delgado-Pertiñez, M., M. J. Alcalde, J. L. Guzman-Guerrero, J. M. Castel, Y. Mena, and F. Caravaca. 2003. Effect of hygiene-sanitary management on goat milk quality in semi-extensive systems in Spain. Small Rumin. Res. 47:51-61.

Droke, E. A., M. J. Paape, and A. L. Di Carlo. 1993. Prevalence of high somatic cell counts in bulk tank goat milk. J. Dairy Sci. 76:1035-1039.

Foschino, R., A. Invernizzi, R. Barucco, and K. Stradiotto. 2002. Microbial composition, including the incidence of pathogens, of goat milk from the Bergamo region of Italy during a lactation year. J. Dairy Res. 69:213-225.

Gonzalo, C., J. A. Carriedo, E. Beneitez, M. T. Juarez, L. F. De La Fuente, and F. San Primitivo. 2006. Short communication: Bulk tank total bacterial count in dairy sheep: Factors of variation and relationship with somatic cell count. J. Dairy Sci. 89:549-552.

Gonzalo, C., J. A. Carriedo, M. A. Blanco, E. Beneitez, M. T. Juarez, L. F. De La Fuente, and F. San Primitivo. 2005. Factors of variation influencing bulk tank somatic cell count in dairy sheep. J. Dairy Sci. 88:969-974.

Haenlein, G. F. W. 2002. Relationship of somatic cell counts in goat milk to mastitis and productivity. Small Rumin. Res. 45:163-178.

Jayarao, B. M., S. R. Pillai, A. A. Sawant, D. R. Wolfgang, and N. V. Hegde. 2004. Guidelines for monitoring bulk tank milk somatic cell and bacterial counts. J. Dairy Sci. 87:3561-3573.
Khaitsa, M. L., T. E. Wittum, K. L. Smith, J. L. Henderson, and K. H. Hoblet. 2000. Herd characteristics and management practices associated with bulk-tank somatic cell counts in herds in official Dairy Herd Improvement Association programs in Ohio. Am. J. Vet. Res. 61:1092-1098.

Luengo, C., A. Sanchez, J. C. Corrales, C. Fernández, and A. Contreras. 2004. Influence of intramammary infection and noninfection factors on somatic cell counts in dairy goats. J. Dairy Res. 71:169-174.

Nord, K., and T. Ådnøy. 1997. Effects of infection by caprine arthritisencephalitis virus on milk production of goats. J. Dairy Sci. 80:2391-2397

Paape, M. J., B. Poutrel, A. Contreras, J. C. Marco, and A. V Capuco. 2001. Milk somatic cells and lactation in small ruminants. J. Dairy Sci. 84:E237-E244.

Paape, M. J., G. R. Wiggans, D. D. Bannerman, D. L. Thomas, A. H. Sanders, A. Contreras, P. Moroni, and R. H. Miller. 2007. Monitoring goat and sheep milk somatic cell counts. Small Rumin. Res. 68:114-125.

Park, Y. W. 1991. Interrelationships between somatic cell counts, electrical conductivity, bacteria counts, percent fat and protein in goat milk. Small Rumin. Res. 5:367-375.

Park, Y. W., and R. D. Humphrey. 1986. Bacterial cell counts in goat milk and their correlations with somatic cell counts, percent fat, and protein. J. Dairy Sci. 69:32-37.

Pinheiro, J., D. Bates, S. DeBroy, and D. Sarkar. 2008. NLME: Linear and nonlinear mixed effects models, $\mathrm{R}$ Project for Statistical Computing, Vienna, Austria.

Pirisi, A., A. Lauret, and J. P. Dubeuf. 2007. Basic and incentive payments for goat and sheep milk in relation to quality. Small Rumin. Res. 68:167-178.

Rysanek, D., and V. Babak. 2005. Bulk tank milk somatic cell count as an indicator of the hygiene status of primary milk production. J. Dairy Res. 72:400-405.

Salama, A. A. K., G. Caja, X. Such, R. Casals, and E. Albanell. 2005. Effect of pregnancy and extended lactation on milk production in dairy goats milked once daily. J. Dairy Sci. 88:3894-3904.

Sargeant, J. M., and S. W. Martin. 1998. The dependence of kappa on attribute prevalence when assessing the repeatability of questionnaire data. Prev. Vet. Med. 34:115-123.

Schukken, Y. H., D. J. Wilson, F. Welcome, L. Garrison-Tikofsky, and R. N. Gonzalez. 2003. Monitoring udder health and milk quality using somatic cell counts. Vet. Res. 34:579-596.

Tirard-Collet, P., J. A. Zee, L. Carmichael, and R. E. Simard. 1991 A study of the microbiological quality of goat milk in Quebec. J. Food Prot. 54:263-266.

Turin, L., G. Pisoni, M. L. Giannino, M. Antonini, S. Rosati, G. Ruffo, and P. Moroni. 2005. Correlation between milk parameters in CAEV seropositive and negative primiparous goats during an eradication program in Italian farm. Small Rumin. Res. 57:73-79.

Valde, J. P., M. L. Lystad, E. Simensen, and O. Østerås. 2007. Comparison of feeding management and body condition of dairy cows in herds with low and high mastitis rates. J. Dairy Sci. 90:4317-4324

Zeng, S. S., and E. N. Escobar. 1995. Effect of parity and milk production on somatic cell count, standard plate count and composition of goat milk. Small Rumin. Res. 17:269-274.

Zeng, S. S., and E. N. Escobar. 1996. Effect of breed and milking method on somatic cell count, standard plate count and composition of goat milk. Small Rumin. Res. 19:169-175.

Zeng, S. S., E. N. Escobar, S. P. Hart, L. Hinckley, M. Baulthaus, G. T. Robinson, and G. Jahnke. 1999a. Comparative study of the effects of testing laboratory, counting method, storage and shipment on somatic cell counts in goat milk. Small Rumin. Res. 31:103-107.

Zeng, S. S., T. Popham, and E. N. Escobar. 1999b. Seasonal variation of somatic cell count and chemical composition in bulk tank goat milk. Dairy Food Environ. Sanit. 19:685-690.

Zweifel, C., J. E. Muehlherr, M. Ring, and R. Stephan. 2005. Influence of different factors in milk production on standard plate count of raw small ruminant's bulk-tank milk in Switzerland. Small Rumin. Res. 58:63-70. 